\title{
SPATIAL TEMPORAL SOWING PATTERN OF RAPESEED-MUSTARD CROP IN INDIA USING MULTI-DATE IRS AWIFS DATA
}

\author{
D.R. Rajak , H.A. Patel, K.N. Chaudhari, N.K. Patel, S. Panigrahy \& J.S. Parihar \\ Earth, Ocean, Atmosphere, Planetary Sciences and Applications Area, \\ Space Applications Centre (ISRO), Ahmedabad-380015, India. \\ (\# rajakdr@sac.isro.gov.in; rajakdr@yahoo.com)
}

KEY WORDS: Rapeseed-Mustard Crop, Crop Sowing Pattern, Remote Sensing, Multi-date IRS P6 AWiFS

\begin{abstract}
:
This paper highlights the results on spatial pattern of sowing of rapeseed/mustard in four major states in India using multidate Advanced Wide Field Sensor (AWiFS) data for 2010-11 crop season. Geo-referenced, calibrated AWiFS data acquired during October 2010 to February 2011 were used to generate the Normalised Difference Vegetation Index (NDVI) image sets. Iterative Self-Organizing Data Analysis Technique (ISODATA) based clustering of the multi date NDVI dataset for mustard crop pixels was performed. The clusters were segregated to spectral emergence classes using a spectral profile matching approach with reference to ground truth data. The sowing dates were derived from the spectral emergence data using a lag period based on field observation. Analysis showed the sowing pattern in the study states is spread over around 60 days from mid October to mid December. Three distinct clusters of sowing pattern were observed. The major one (around 40\%) is sown between mid October and first week of November. Around $25 \%$ area is sown from last week of November to mid December. The other 35\% area is sown in between these two periods. Analysis of temperature, a key weather variable influencing the growth of this crop, showed that the crop sowing in northern Rajasthan and Haryana is delayed by about one month to avoid the frost damage during reproductive phase. In the parts of Gujarat, southern parts of Rajasthan and Madhya Pradesh (MP), an early sowing in the second fortnight of October was observed, mainly to avoid higher mean temperatures during the month of March.
\end{abstract}

\section{INTRODUCTION}

Rapeseed/mustard is the third major oilseed of India, ranking after groundnut and soybean, with around 23 per cent share of all oilseed production. The crop is mainly grown during the winter season (October-March). The major growing states are Rajasthan, Uttar Pradesh, Haryana, Madhya Pradesh (MP), Assam and West Bengal. The productivity of the mustard crop shows significant inter-annual fluctuation being subjected to moisture stress, pest and disease incidence etc. Research findings have shown that sowing date is one of the critical components affecting mustard crop productivity. The recommended sowing calendar for mustard varies across the major growing regions. Some researchers demonstrated that the yield of mustard crop sown in second fortnight of September was significantly higher than that sown in first fortnight of October (Iraddi, 2008). In general, it was observed that the mustard crop sown after October 30th resulted in lower yields (Panwar et al., 2000; Raj Singh et al., 2001; Raj Singh et al., 2002; Sonani et al., 2002; Panda et al., 2004a; Panda et al., 2004b). Sowing period information is also needed for various other purposes like adjusting crop rotations; cropping patterns, crop growth simulations and climate change impact studies. However, very little information is available on the actual sowing pattern of this crop, particularly in a spatial domain. Advanced techniques of satellite remote sensing and Geographic Information System (GIS) are now available to derive spatial pattern of crop area, cropping pattern change, crop calendar and crop rotation etc. (Navalgund et al., 1991; Parihar and Dadhwal, 2002; Rajak et al., 2002; Rajak et al., 2008; Panigrahy et al, 2005; Panigrahy \& Sharma, 1997; Patel et al., 2004). High temporal resolution data is essential to analyze the crop calendar. Indian Remote Sensing Satellite (IRS) AWiFS data has been used to derive the mustard crop acreage at state and regional level under the FASAL (Forecasting Agriculture using Space, Agrometeorology \& Land based observation) project of Department of Agriculture \& Cooperation, Government of India. This paper highlights the methodology used to derive the spatial pattern of the sowing period of rapeseed/mustard in the major growing states of India.

\section{STUDY AREA AND DATA USED}

The four major mustard growing states of India namely Rajasthan, Haryana, MP and Gujarat forms the study area (Fig.1) These four states produce almost $80 \%$ of the national mustard. IRS AWiFS data with $56 \mathrm{~m}$ spatial resolution and wide swath of $700 \mathrm{~km}$ was used for this study. Multi-date geo-referenced AWiFS data acquired during October 2009 to February 2010 has been used as this data set was found optimum for mustard crop identification (Parihar and Oza, 2006). The details of the dataset are given in Table 1. The mustard crop layer, available from another project was used in this study. Field data collected on crop stage, percent cover, vigour using Global Positioning System (GPS) receiver were used to model and validate the crop sowing period.

\section{METHODOLOGY}

The major steps of methodology are: preparation of multi-date Normalized Difference Vegetation Index (NDVI) images from geo-referenced multi-date AWiFS data, use of mustard crop mask, Iterative Self-Organizing Data Analysis Technique (ISODATA) based clustering of multi date NDVI within the crop mask, assigning the clusters to early, timely and late sown 
ISPRS Archives XXXVIII- 8/W20; Workshop Proceedings: Earth Observation for Terrestrial Ecosystems

categories using ground truth data and generation of crop sowing map. The methodology adopted in this study is shown in Figure 2.

\subsection{Multi-date NDVI Dataset Preparation}

The raw digital numbers $(\mathrm{DN})$ images from $\mathrm{AWiFS}$ data were converted to radiance images using the calibration coefficients. The relationship between DN and radiance $(\mathrm{L})$ is given by:

$\mathrm{L}=\mathrm{L}_{\min }+\mathrm{DN} *\left(\mathrm{~L}_{\max }-\mathrm{L}_{\min }\right) / \mathrm{DN}_{\max }$

Where,

$\mathrm{L}_{\min }=$ minimum radiance

$\mathrm{L}_{\max }=$ saturation radiance/maximum radiance

$\mathrm{DN}_{\max }=$ Radiometric resolution

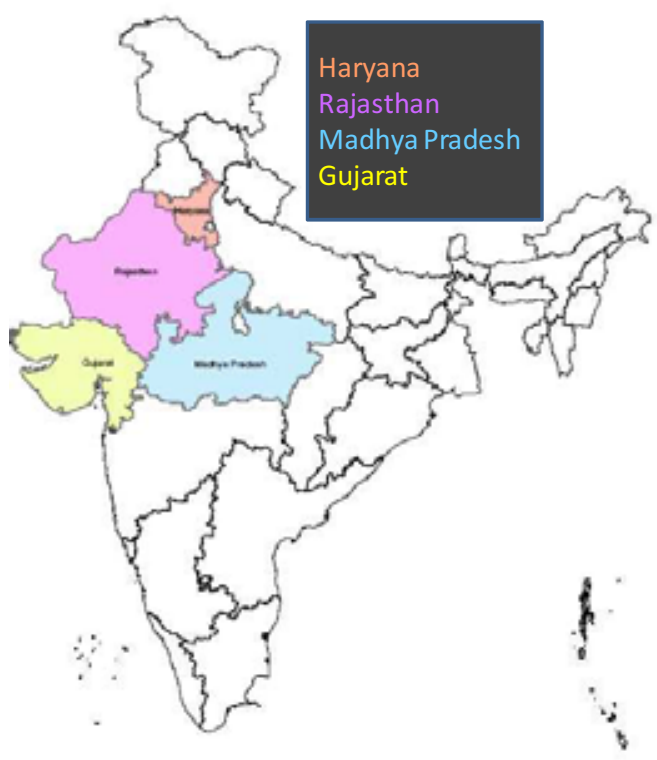

Fig. 1: Study States selected for the study (Rajasthan, Haryana, Gujarat \& MP States)

\begin{tabular}{|c|c|c|c|c|c|c|c|}
\hline $\begin{array}{c}\text { Sr. } \\
\text { No }\end{array}$ & Path & Row & $\begin{array}{c}\text { Date of } \\
\text { Pass }\end{array}$ & $\begin{array}{c}\text { Sr. } \\
\text { No }\end{array}$ & Path & Row & $\begin{array}{c}\text { Date of } \\
\text { Pass }\end{array}$ \\
\hline 1 & 96 & 51 & $13-$ Oct-10 & 16 & 95 & 51 & 19-Dec-10 \\
\hline 2 & 92 & 54 & $17-$ Oct-10 & 17 & 100 & 53 & 20-Dec-10 \\
\hline 3 & 93 & 54 & $22-$-Oct-10 & 18 & 101 & 53 & 25-Dec-10 \\
\hline 4 & 98 & 52 & $23-O c t-10$ & 19 & 93 & 54 & 2-Jan-11 \\
\hline 5 & 94 & 51 & $27-O c t-10$ & 20 & 95 & 51 & 12-Jan-11 \\
\hline 6 & 91 & 50 & 5-Nov-10 & 21 & 93 & 51 & 26-Jan-11 \\
\hline 7 & 91 & 54 & 5-Nov-10 & 22 & 98 & 52 & 27-Jan-11 \\
\hline 8 & 96 & 51 & 6-Nov-10 & 23 & 99 & 53 & 1-Feb-11 \\
\hline 9 & 99 & 53 & $21-N o v-10$ & 24 & 95 & 51 & 5-Feb-11 \\
\hline 10 & 91 & 54 & $29-$-Nov-10 & 25 & 91 & 54 & 9-Feb-11 \\
\hline 11 & 96 & 51 & 30-Nov-10 & 26 & 96 & 51 & 10-Feb-11 \\
\hline 12 & 92 & 50 & 4-Dec-10 & 27 & 93 & 51 & 19-Feb-11 \\
\hline 13 & 97 & 52 & 5-Dec-10 & 28 & 89 & 53 & 23-Feb-11 \\
\hline 14 & 93 & 51 & 9-Dec-10 & 29 & 90 & 54 & 28-Feb-11 \\
\hline 15 & 90 & 54 & 18-Dec-10 & & & & \\
\hline
\end{tabular}

Table 1: Details of multi-date AWiFS data used
The values of $\mathrm{L}_{\max }$ and $\mathrm{L}_{\min }$ for different spectral bands of the AWiFS sensor ars given in Table 2. The values of $\mathrm{DN}_{\max }$ were taken as 1024 for AWiFS (10 bit data). NDVI values derived from these radiance values of two spectral bands, is defined as:

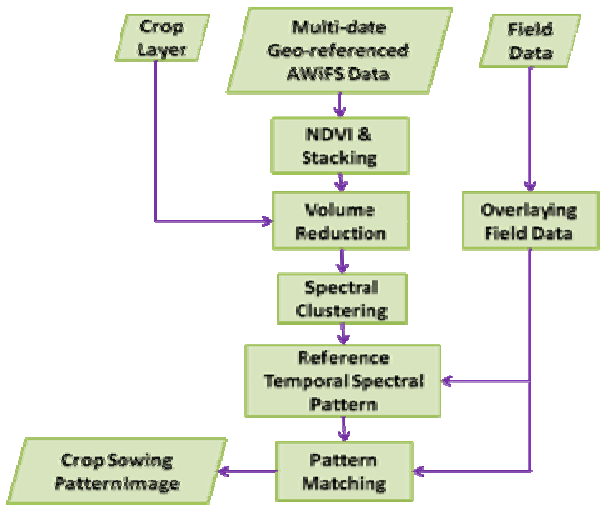

Fig. 2: Flow Chart of the methodology followed for data analysis.

$$
N D V I=\frac{L_{N I R}-L_{R}}{L_{N I R}+L_{R}}
$$

\begin{tabular}{|l|l|l|l|}
\hline Spectral Band & Band $\boldsymbol{\lambda}$ Range $(\boldsymbol{\mu m})$ & $\mathbf{L}_{\max } \#$ & $\mathbf{L}_{\min }$ \\
\hline Green & $0.52-0.59$ & 53.0 & 0 \\
\hline Red & $0.62-0.68$ & 47.0 & 0 \\
\hline NIR & $0.77-0.86$ & 31.5 & 0 \\
\hline SWIR & $1.55-1.70$ & 07.5 & 0 \\
\hline
\end{tabular}

\# Lmax and Lmin in mw/sq.cm/str/micron

Table 2: Calibration coefficients of AWiFS used for computing radiance values

$\mathrm{L}_{\mathrm{NIR}}$ is radiance value for NIR (Near Infra Red) band and $\mathrm{L}_{\mathrm{R}}$ is radiance value for red band. The range of NDVI values varies from -1.0 to +1.0 . For simplicity; it was scaled in the range of 0 to 200 by multiplying 100 and adding 100 .

Scaled NDVI $=100+100 \times($ NDVI)

The NDVI images of all dates were stacked together in time sequence to form time-series dataset of NDVI images. Figure 3 shows multi-date AWiFS data over Haryana state.

\subsection{Clustering of Multi-date Spectral Data}

Unsupervised classification using ISODATA clustering was used to form data clusters in spectral domain. Clustering is based on the natural grouping of pixels in image data when they are plotted in feature space. According to the specified parameters, these groups can later be merged, manipulated, or used as the basis of a signature. The ISODATA method uses minimum spectral distance to assign a cluster for each candidate pixel. The process begins with a specified number of arbitrary cluster means or the means of existing signatures, and then it processes repetitively, so that those means shift to the means of the clusters in the data. 
ISPRS Archives XXXVIII- 8/W20; Workshop Proceedings: Earth Observation for Terrestrial Ecosystems

Being iterative process, clustering is not geographically biased to the top or bottom pixels of the data file. Although it may be timeconsuming method in few cases, this algorithm is highly successful at finding the spectral clusters that are inherent in the data.

The first iteration starts with determining means of $\mathrm{N}$ clusters arbitrarily. Second iteration and onwards, a new mean for each cluster is calculated, based on the actual spectral locations of the pixels in the cluster, instead of the initial arbitrary calculation. These new means are used for defining clusters in the next iteration. The process continues until there is little change between iterations (Swain, 1973). The initial cluster means are distributed in feature space along a vector that runs between the points at spectral coordinates

$\left(\mu_{1}-\sigma_{1}, \mu_{2}-\sigma_{2}, \mu_{3}-\sigma_{3}, \ldots \mu_{n}-\sigma_{n}\right)$ and

$\left(\mu_{1}+\sigma_{1}, \mu_{2}+\sigma_{2}, \mu_{3}+\sigma_{3}, \ldots \mu_{\mathrm{n}}+\sigma_{\mathrm{n}}\right)$.

The initial cluster means are evenly distributed between $\left(\mu_{\mathrm{A}}-\sigma_{\mathrm{A}}\right.$, $\left.\mu_{\mathrm{B}}-\sigma_{\mathrm{B}}\right)$ and $\left(\mu_{\mathrm{A}}+\sigma_{\mathrm{A}}, \mu_{\mathrm{B}}+\sigma_{\mathrm{B}}\right)$.

In above coordinates, $\mu_{\mathrm{n}}$ and $\sigma_{\mathrm{n}}$ stands for mean and standard deviation values for $\mathrm{n}^{\text {th }}$ cluster, respectively; whereas $\mu_{\mathrm{A}}$ and $\sigma_{\mathrm{A}}$ refers to mean and standard deviation values in spectral bands $\mathrm{A}$ and $\mathrm{B}$, respectively.

In the present study, six spectral clusters were formed for each sub-tile $\left(2^{\circ} \times 2^{\circ}\right.$ spatial extent) pixels belonging to mustard crop. The limiting degree of convergence was given 0.99 and the maximum number of iterations allowed was 20 . In all the cases, the process ran to complete 20 iterations and the degree of convergence achieved was better than 0.98 .

\subsection{Overlaying Field Data on RS Images}

The coordinates of locations where field information was collected during crop growing period, were transformed to vector coverage form to make it image processing compatible. This vector coverage was overlaid on the images and the locations with varying sowing patterns were identified. Areas of interest (AOI) were marked on one image and the cloud clearness of images of other dates was verified for those locations.

\subsection{Generation of Reference Temporal Spectral Patterns (RTSP)}

Multi-date signatures of mustard crop pixels in terms of scaled NDVI values for all the 'areas of interest' (AOI) marked in previous step were extracted from stacked NDVI dataset. The signatures extracted from all the sub-tiles were put together and an assembled dataset was prepared. Temporal variations of NDVI values for all locations were plotted on scatter plot and range of crop spectral emergence date (assumed at the day when NDVI value reaches to 0.2 after sowing) was determined. The range of crop emergence day was divided by 3 to get threshold NDVI values corresponding to early, timely and late emerged mustard crop (and hence early, timely and late sown crop). These patterns were termed as Reference Temporal Spectral Patterns (RTSP).

\subsection{Assigning Temporal Spectral Clusters to RTSPss}

The mean values of spectral clusters formed by ISODATA algorithm were plotted against date and temporal spectral variations of these clusters were compared with temporal spectral variations of RTSPs. Based on the visual matching of patterns the clusters were assigned to early, timely or late emerged/sown categories of mustard crop.

\subsection{Aggregation of Crop Acreages under Each Category}

Pixels corresponding to each cluster were assigned unique digital numbers based on the ISODATA cluster category. All the pixels belonging to early emerged/sown category were assigned a value of 1 , while those belonging to timely and late emerged/sown categories were assigned values of 2 and 3, respectively. This step was repeated for all the study sub-tiles and a mosaic of such classified images over study area of four states was prepared. The histogram of this image provided the statistics of early, timely and late emergent/sown mustard crop in the state. It was assumed that mustard crop takes around 15 days after sowing to emergence from soil and to be detected by remote sensors.

\subsection{Validation}

The validation of mustard sowing pattern was carried out by comparing the dates of sowing obtained by RS data analysis with those collected during in-season field in study area.

\subsection{Analysis of Temporal Spatial Temperature Variations}

Temperature is the key weather variable that governs the growth of the temperature sensitive crops like mustard. Analysis of fortnightly temperatures (minimum, maximum and mean), over the study area throughout the crop season was carried out to understand the correlation of sowing date to these parameters.

\section{RESULTS AND DISCUSSION}

The temporal NDVI values corresponding to locations of the field observation were compared to study the variation among sowing patterns obtained from ground data. These patterns were used as reference patterns while assigning class names to different ISODATA clusters. Figure 4 shows three of such reference RTSPs, each one for early, timely and late emerged/sown mustard crop. Similar to RTSPs, the temporal behaviour of mean values of ISODATA clusters were plotted on temporal domain for pattern matching purpose. Temporal NDVI patterns of ISODATA clusters after classification are shown in Figure 5.

The range of mustard crop sowing dates over study area was found to be 60 days. It provided the threshold values for early, timely and late emergent/sown crop. Based on the aggregation of acreage under the three categories following observations about the three categories of crop sowing dates may be made:

- $\quad$ Early sown mustard area - In this area mustard crop sowing time varies from mid October to first week of November in the districts of Bharatpur, Kota, Baran, Jhalawar, Sawaimadhopur, Dhaulpur, Morena, Bhind, Gwalior etc. It forms $40 \%$ area of total mustard area of the study area. 
- Timely sown mustard area - Major parts of Tonk, Alwar, Dausa, Karauli, Jodhpur, Banaskantha, Mehsana, Patan, Bhiwani and Rewari districrs fall In this category. The crop is sown from first and fourth week of November in this region. It forms almost $35 \%$ of total mustard area.

- Late sown mustard area - In major parts of Ganganagar, Hanumangarh, Jaipur, Jhunjhunun and Sikar, Hisar and Sirsa districts mustard crop is sown between fourth week of November to mid December and this region contributes 25\% of mustard acreage. The spatial distributions of sowing of rapeseed mustard crop in the four study states of India are shown in Figure 6.

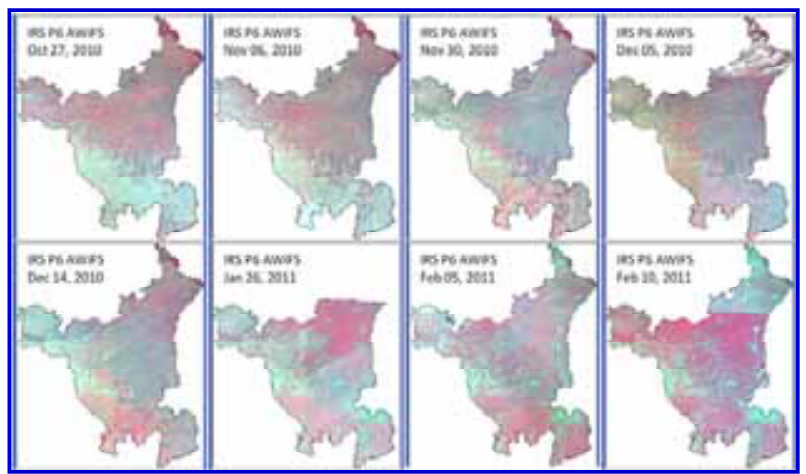

Fig. 3: Multi-date AWiFS Mosaic Images (Dates+5days) over Haryana state.

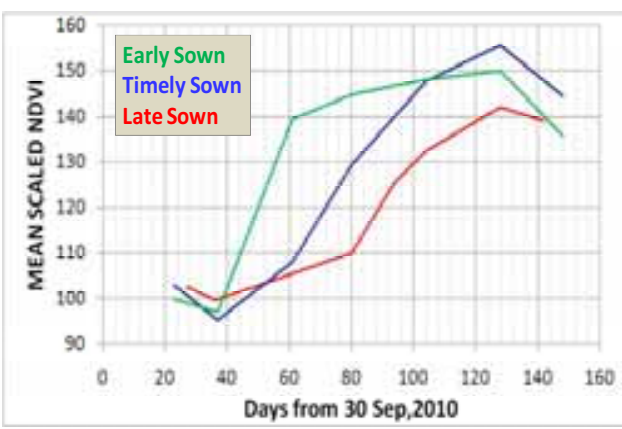

Fig. 4: Three of Reference Temporal Spectral Profiles

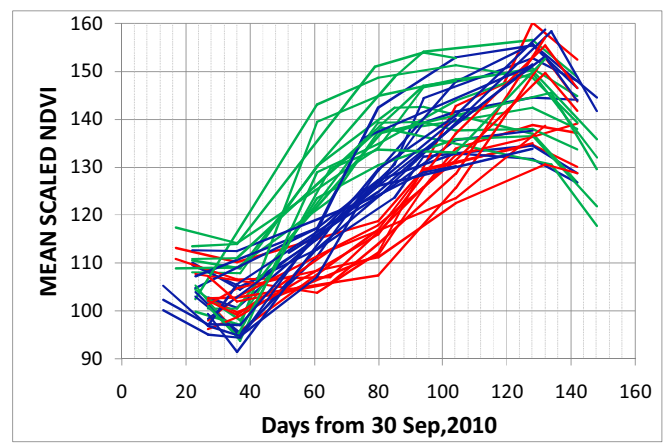

Fig. 5: ISODATA Clusters Temporal Spectral Profiles
The temporal spatial analysis of different temperatures over India showed that the sowing period of rapeseed-mustard in a particular region is governed by the prevailing temperatures during reproductive period and not by the temperatures during the sowing time. Rapeseed-mustard crop requires optimum average day and night temperature around $25^{\circ} \mathrm{C}$ for better germination (Haberlandt, cited by Bierhuzen, 1973). Though, the required temperature prevails during the second fortnight of October and it was also recommended as the optimal period for sowing over the region by many researchers, the farmers in northern Rajasthan and Haryana delays crop sowing by about one month to avoid the frost damage during reproductive phase (Figure 7a). Thus, a latitudinal variation in sowing date emerged. In the parts of lower latitudes viz. Gujarat, southern parts of Rajasthan and MP, where there is no-risk of frost damage an early sowing in the second fortnight of October was observed that also avoids crop to face higher mean temperatures during the month of March (Figure 7b).

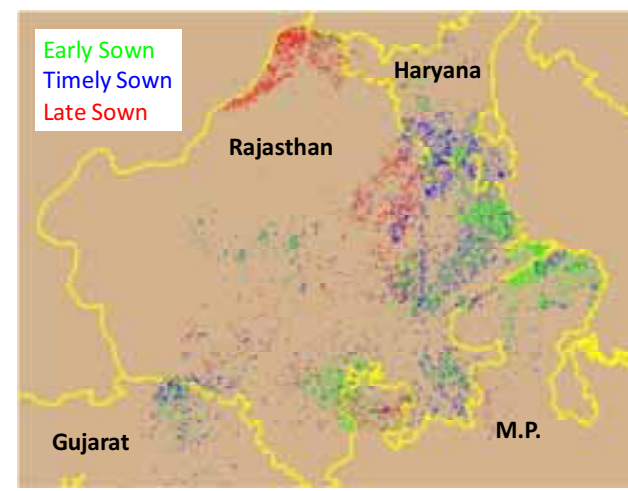

Fig. 6: Spatial Crop Sowing Pattern of Mustard Crop: Study States, India

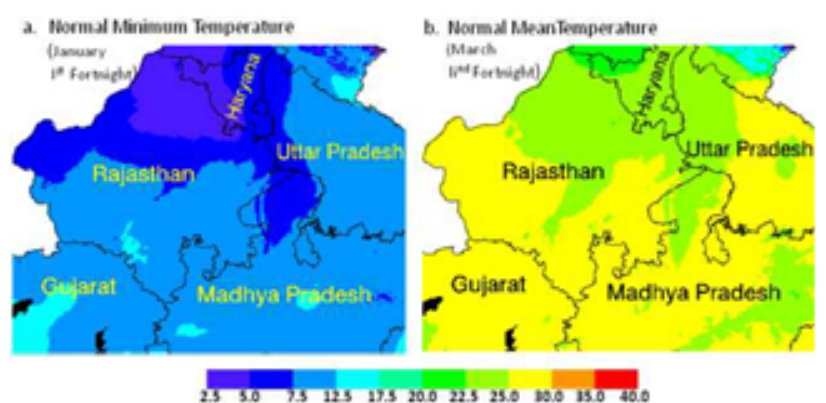

Fig. 7: Normal minimum and mean temperatures over the study area

\section{CONCLUSION}

A multi-date IRS P6 AWiFS data based approach has been developed for capturing the spatial variation in sowing pattern of mustard crop across four of the major crop growing states in India. The approach is based on ISODATA clustering of multidate NDVI stacked data derived from AWiFS data of 2010-11 rabi season. Temporal spectral patterns matching between ISODATA clusters and Reference Temporal Spectral Patterns derived based on in-season field data was carried out to label 
ISPRS Archives XXXVIII- 8/W20; Workshop Proceedings: Earth Observation for Terrestrial Ecosystems

ISODATA clusters to three categories i.e. early, timely and late sown mustard crop. The result showed that mustard crop sowing in these four states of India varied from mid October to mid December. The proportion of early sown mustard (sowing between mid October and first week of November) was found to be $40 \%$ and that of timely sown (sowing between first and fourth week of November) was $35 \%$ and late sown (sowing fourth week of November onwards) mustard was found to be $25 \%$ each. The latitudinal variation in sowing date is due to adapted delay in sowing to avoid frost damage during reproductive phase and to avoid facing higher mean temperatures during the month of March

\section{REFERENCES}

Bierhuzen, J.F., 1973. The effect of temperature on plant growth, development and yield. In "Plant response to climate factors" Edited by R.O. Slatyer, UNESCO, Paris, 1973: pp.89-97.

Iraddi, V.S., 2008. Response of Mustard (Brassica juncea L. Czernj and Cosson) Varietis to Date of Sowing and Row Spacing in Northern Transition Zone of Karnataka. Abstracts of Thesis Accepted for the Award of Post-Graduate Degree in the University of Agricultural sciences, Dharwad. Karnataka J. Agric. Sci., 21 (4).

Navalgund, R.R., Parihar J.S., Ajai and Nageshwara Rao, P.P., 1991. Crop inventory using remotely sensed data. Current Science, vol. 61, pp. 162-171.

Panda, B. B., Bandyopadhyay, S. K. and Shivay, Y. S., 2004a. Effect of irrigation level, sowing dates and varieties on growth, yield attributes, yield, consumptive water use and water use efficiency of Indian mustard (Brassica juncea). Ind. J. Agric. Sci., 74(6) :331-342.

Panda, B. B., Shivay, Y. S. and Bandyopadhyay, S. K., $2004 \mathrm{~b}$. Growth and development of Indian mustard (Brassica juncea) under different levels of irrigation and date of sowing. Ind. J. Pl. Physiol., 9(4) : 419-425.

Panigrahy, S. and S. A. Sharma , 1997. Crop rotation mapping using IRS 1C LISS-I data. ISPRS Journal of Photogramm.\& Rem. Sens.,52, pp. 234-237.

Panigrahy, S., Manjunath, K.R. and Ray, S. S., 2005. Deriving cropping system performance indices using remote sensing and GIS. int. j. rem. sens. 26(12): pp. 2595-1606.

Panwar, K. S., Sharma, S. K. and nanwal, R. K., 2000. Influence of sowing times on the yield of different mustard cultivars (Brassica spp.) under conserved soil moisture conditions. Ind. J. Agric. Sci., 70(6) : pp. 398-399.

Parihar, J. S. and Dadhwal, V. K., 2002. Crop production forecasting using remote sensing data: Indian experience. Proceedings of the ISPRS Comm. VII Symposium "Resource and
Environmental Monitoring" held at Hyderabad, India during Dec. 3-6 2002, IAPRS \& GIS, vol. 34, Part 7, pp. 1-6.

Parihar, J.S., and Oza, M. P., 2006. FASAL: an integrated approach for crop assessment and production forecasting. Agriculture and Hydrology Applications of Remote Sensing, edited by Robert J. Kuligowski, Jai S. Parihar, Genya Saito, Proc. of SPIE Vol. 6411, 641101, (2006) • 0277-786X/06/\$15 doi: 10.1117/12.713157 Proc. of SPIE Vol. 6411 641101-1.

Patel, N.K., Chakraborty, M., Dutta, S., Patnaik, C., Parihar, J.S., Moharana, S.C., Das, A., Sarangi, B.K. and Behra, G., 2004. Multiple forecasts of kharif rice in Orissa state - Four year experience of FASAL pilot study. Journal of the Indian Society of Remote Sensing, 32, pp. 125-143.

Raj Singh, Patidar, M. and Singh, B., 2001. Response of Indian mustard cultivars to different sowing time. Ind. J. Agron., 46(2), pp. 292-295.

Raj Singh, Rao, V. U. M., Diwan Singh and Surakant, 2002. Effect of sowing date and plant density on phonological behaviour, yield and its attributes in oilseed Brassicae. J. Oilseeds Res., 19(1) : 119-121.

Rajak D. R., Patel G. N., Bhagia N., Dutta S. and Patel N. K., 2008. A Hybrid Technique of Crop Classification Using Multidate AWiFS Data. XXVIII INCA International Congress, Gandhinagar, Gujarat, India, November 4-6, 2008.

Rajak D.R., Oza M.P., Bhagia N. and Dadhwal V.K., 2002. Monitoring Cropping Pattern Changes Using Multi-temporal WiFS Data. Geocarto International, 17 (3), 51-56.

Rajendra Kumar and Shaktawat, M. J., 1992. Effect of limited water supply, nitrogen and time of sowing on production of rapeseed (Brassica napus). Ind. J. Agron., 37(4) : 853-855.

Sonani, V. V., Patel, P. T. and Patel, G. G., 2002. Performance of mustard under different dates of sowing in Bhal and Coastal Agro-climatic zone of Gujarat., J. Oilseeds Res., 19(1) : 122.

Swain, P. H., 1973. Pattern Recognition: A Basis for Remote Sensing Data Analysis (LARS Information Note 111572). West Lafayette, Indiana: The Laboratory for Applications of Remote Sensing, Purdue University.

\section{ACKNOWLEDGEMENTS}

The study was carried out under FASAL (Forecasting Agricultural output using Space, Agrometeorology and Land based observations) project, which is funded by Ministry of Agriculture, Government of India. Authors are grateful to Dr. R. R. Navalgund, Director - Space Applications Centre (SAC), Ahmedabad for providing constant encouragement to carry out this study. 